\title{
Resíduos de construção e demolição: avaliação de métodos de quantificação
}

\section{Construction and demolition waste: evaluation of quantification methods}

\author{
Sérgio Cirelli Angulo \\ Engenheiro Civil. Doutor em Engenharia Civil. Pesquisador do Instituto de Pesquisas Tecnológicas do Estado de São Paulo SA. Professor do Departamento \\ de Engenharia de Construção Civil da Escola Politécnica da Universidade de São Paulo
}

Cláudia Echevenguá Teixeira

Bióloga. Doutora em Engenharia Ambiental. Pesquisadora do Instituto de Pesquisas Tecnológicas do Estado de São Paulo SA. Professora do Programa de Pós-Graduação em Administração da Universidade Nove de Julho (UNINOVE)

\section{Alessandra Lorenzetti de Castro \\ Engenheira Civil. Doutora em Engenharia Civil. Pesquisadora do Instituto de Pesquisas Tecnológicas do Estado de São Paulo SA}

\section{Thais Passos Nogueira}

Tecnóloga Ambiental. Colaboradora do Instituto de Pesquisas Tecnológicas do Estado de São Paulo SA

\begin{abstract}
Resumo
Neste trabalho, estimou-se a geração dos resíduos de construção e demolição por dois métodos de quantificação, um indireto e outro direto, considerandose a produção advinda dos agentes informais e formais. O método indireto considerou a área construída das edificações (construção) e transformação dos pontos de ligação de água e luz instalados (reforma). O método direto identificou a geração advinda de agentes informais e formais nos pontos de disposição finais em diferentes regiões do município, empregando-se o conceito de balanço de massa. Não é possível quantificar a geração de resíduos de construção e demolição dos agentes informais (reformas) por meio de dados indiretos relacionados às transformações dos pontos de água no município. Há indícios de que as transformações dos pontos de energia elétrica sejam um indicador indireto mais preciso, podendo evitar a dispendiosa quantificação direta.
\end{abstract}

Palavras-chave: resíduos de construção e demolição; métodos de quantificação; método direto; método indireto; balanço de massa; geradores informais.

\section{Abstract}

In this paper, construction and demolition waste generation was estimated by two quantification methods, one direct and other indirect, regarding informal and formal generators. Construction area and transformation of the points of water and energy were applied for indirect quantification method. For the direct one volume of dumping areas associated with informal and formal generators in different regions of municipality were quantified and the mass balance was applied. Indirect quantification of informal generators by transformation points of water is not precise. There are evidences that transformation points of energy can be more precise, avoiding costly direct construction and demolition waste quantification method.

Keywords: construction and demolition waste; quantification methods; direct method; indirect method; mass balance; informal generators

\section{Introdução}

Os resíduos da construção e demolição (RCD) são gerados nas atividades de construção, reforma ou demolição e constituídos por um conjunto de materiais, tais como: tijolos, blocos cerâmicos, concreto em geral, madeiras e compensados, argamassa, gesso, entre outros (CONAMA, 2002; ANGULO, 2005). Os RCD, pela resolução CONAMA 307, são classificados em quatro classes, a saber: Classe A (RCD recicláveis como os agregados); B (RCD recicláveis para outras destinações como plásticos, papel/papelão, metais, entre outros); C (RCD sem tecnologia disponível para reciclagem e aproveitamento como o gesso) e D (RCD perigosos como tintas, solventes, óleos, fibrocimentos com amianto, entre outros).

Os RCD representam, em média, 50\% da massa dos resíduos sólidos urbanos (PINTO, 1999; JOHN, 2000), tanto no Brasil como em outros países. As disposições irregulares e os aterros clandestinos, ocasionados pela falta de gerenciamento, tornaram-se uma realidade no território nacional. Em 2002, com a aprovação da resolução 307, 
ficaram estabelecidos critérios e procedimentos para a gestão de RCD no Brasil (CONAMA, 2002). Por esta resolução, são atribuídas responsabilidades tanto para o poder público quanto para a iniciativa privada (PINTO et al., 2005). As empresas privadas de construção, que são grandes geradoras desse resíduo, devem desenvolver projetos de gerenciamento específicos, por exemplo, triagem em canteiros de obras, incluindo o uso de transportadores cadastrados e de áreas licenciadas para manejo e reciclagem. O poder público deve oferecer uma rede de coleta e destinação ambientalmente correta para os pequenos geradores, responsáveis por reformas e autoconstruções e incapazes de implementar autogestão.

Costa et al. (2007) constataram a influência de variáveis (socioconômicas, político-legais, de gestão municipal etc.), por análise estatística multivariada, na implantação e no sucesso dos programas de reciclagem de RCD em municípios brasileiros. Das 20 variáveis estudadas, as seis identificadas como mais significativas estão associadas à gestão pública, a saber: percentual dos funcionários de nível médio que trabalham na Prefeitura; renda média anual do município; percentual de domicílios com água; existência de programas de coleta seletiva de lixo; programas de incentivo para geração de trabalho e renda e existência de áreas de recepção de RCD.

Em termos de gerenciamento destes resíduos, é etapa-chave a realização de um diagnóstico, que seja capaz de identificar e quantificar a geração pelos diferentes agentes, informação necessária para elaborar planos de gerenciamento dos RCD. O dimensionamento dos sistemas de gerenciamento depende da identificação das áreas de disposição irregulares nas diferentes localidades e do dimensionamento de unidades de triagem e reciclagem (PINTO, 1999; PINTO et al., 2005). O RCD, por ser constituído de uma gama de diferentes materiais, deve ser triado, de acordo com rotas distintas de reciclagem, sendo dispostos apenas os resíduos perigosos ou aqueles sem alternativas de reciclagem comercialmente disponíveis (CONAMA, 2002).

Em vários países, diversos autores buscam implementar metodologias mais precisas para se quantificar e usar tais informações nas estratégias de gerenciamento dos RCD (HSIAO et al., 2002; WANG et al., 2004; COCHRAN et al., 2007; COCHRAN; TOWSEND, 2010; LAGE et al., 2010; LLATAS, 2011). A metodologia de quantificação geralmente emprega índices de geração dos RCD por unidade de área, dependendo da origem (construção, reforma e demolição). A quantificação precisa sempre foi um desafio e tema relevante a ser investigado.

No Brasil, a tarefa de quantificação é ainda mais difícil. Diferentemente de outros países, uma importante fonte na geração dos RCD são os geradores informais, para os quais dados estatísticos estão indisponíveis e podem representar uma parcela importante dos RCD gerados em um município (PINTO, 1999; PINTO et al., 2005).

Alguns estudos, visando estimar a geração de RCD a partir de construção, foram realizados no Brasil (PINTO, 1999; SOUZA et al., 2004; CARELI, 2008). Nesses estudos, foram obtidas gerações de RCD por unidade de área (em $\mathrm{m}^{2}$ ) de edificações verticais, variando entre 0,050 e $0,150 \mathrm{t} / \mathrm{m}^{2}$. Tal variação depende do controle da produção implementado em cada canteiro de obra. Com relação à geração de RCD a partir de reformas, não existem levantamentos abrangentes. O único estudo identificado foi o de Morales, Mendes e Angulo (2006). Estes autores obtiveram os RCD por unidade de área de reforma (em $\mathrm{m}^{2}$ ) de $0,470 \mathrm{t} / \mathrm{m}^{2}$.

A publicação da resolução CONAMA 307 motivou alguns municípios a implantarem planos de gerenciamento. Contudo, de acordo com o levantamento de Pinto (2008), dos 5.565 municípios existentes no país (IBGE, 2010), apenas 50 implantaram planos de gerenciamento. Um levantamento recente sobre usinas brasileiras de reciclagem de RCD mostrou que essas usinas, operando nas capacidades máximas, conseguiriam reciclar apenas cerca de 4,5\% do RCD gerado (MIRANDA, ANGULO; CARELI, 2009).

Aproximadamente 90\% dos municípios brasileiros possuem menos de 20.000 habitantes (IBGE, 2010), nos quais uma grande parcela de RCD não está sendo devidamente gerenciada dentro do que preconiza a resolução CONAMA 307 (CONAMA, 2002). Dentre as dificuldades apontadas para a implantação dos planos de gerenciamento de RCD, Marques Neto (2009) destaca a falta de recursos financeiros e a inexistência de corpo técnico qualificado nos quadros profissionais capazes de diagnosticar fontes geradoras e implementar ações, como a fiscalização.

A questão dos recursos financeiros atualmente vem sendo vencida por meio dos planos integrados de gerenciamento, envolvendo um grupo de municípios geralmente vinculados à gestão de bacias hidrográficas. Tais práticas são condizentes com a Política Nacional de Resíduos Sólidos, aprovada em 2010 - Lei 12.305 (BRASIL, 2010). Autores como Marques Neto (2009) e Benvenuto e Suzuki (2009) abordam com maiores detalhes esta questão. Entretanto, não há muita pesquisa relacionada à prevenção da geração dos agentes informais e à identificação deles dentro dos municípios.

Dentro deste contexto, este artigo apresenta uma investigação da geração de RCD em um município de 36.300 habitantes na região Noroeste do estado de São Paulo, visando avaliar métodos de quantificação, um indireto e outro direto, considerando a produção advinda dos agentes informais (reforma) e formais (construção). O método indireto quantifica a geração de RCD em massa, considerando a área construída das edificações (construção) e a transformação dos pontos de ligação de água e luz instalados (reforma). O outro método quantifica a geração de RCD em volume, identificando-se a geração advinda dos agentes informais (reforma) e formais (construção) nas proximidades dos pontos de disposição finais, nas diferentes regiões do município. Empregando-se o conceito do balanço de massa, a geração dos agentes é acumulada, respeitando-se a lei de conservação de massas e considerando-se as quantidades de resíduos geradas nos diferentes estágios da análise (WANG et 
al., 2004). Os resultados obtidos pelos dois métodos foram comparados para avaliação de consistência. Além da quantificação, este trabalho apresenta os resultados obtidos em relação à composição dos RCD obtidos.

\section{Métodos}

\section{Classificação dos geradores}

No estudo, os agentes geradores dos RCD foram classificados em três tipos:

1. agente formal de construção: empresas legalizadas, responsáveis pela geração de grandes volumes $\left(>3 \mathrm{~m}^{3}\right)$;

2. agente informal de grande reforma: pessoas que realizam ampliação ou reformas em residências já legalizadas e que geram grandes volumes ( $\left.>3 \mathrm{~m}^{3}\right)$; e

3. agente informal de pequena reforma: pessoas que realizam ampliação ou reformas em residências já legalizadas e que geram pequenos volumes $\left(<3 \mathrm{~m}^{3}\right)$.

Ressalta-se que não há empresas de demolição operando no município, realidade semelhante à maioria dos pequenos municípios brasileiros, e que $3 \mathrm{~m}^{3}$ é o volume de caçamba adotado pelos prestadores de serviço de coleta dos RCD no município estudado. O objetivo da adoção deste volume, como referência, foi devido ao fato de que, quando a geração é superior a este, o proprietário da residência normalmente contrata serviço de coleta, devido à fiscalização municipal.

\section{Quantificação do RCD pelo método indireto}

\section{Construção}

A área construída no município foi analisada durante três anos (2007, 2008 e 2009) em função dos alvarás de construção emitidos. A geração anual acumulada de resíduos na construção (C) foi estimada por dados obtidos ao longo dos meses, empregando-se a Equação 1. Esta quantifica a massa de resíduo por mês, multiplicando-se a área construída mensalmente por um índice de geração de RCD, por unidade de área ( $\mathrm{m}^{2}$ construído). Essa forma de cálculo é a usualmente empregada internacionalmente, conforme é discutido por Cochran et al. (2007) e Solis-Guzman et al. (2009).

$\mathrm{C}=\mathrm{A}_{\mathrm{C}} \times \rho_{\mathrm{C}}$

Equação 1

onde:

C: resíduo na construção por mês (t RCD/mês);

$A_{C}$ : área construída por mês ( $m^{2}$ construído/mês);

$\rho_{C}$ : índice de geração de resíduo na construção $\left(0,150\right.$ t RCD $/ \mathrm{m}^{2}$ construído), obtido por Pinto (1999).

\section{Reforma}

Pinto (1999) comenta a possibilidade do uso de indicadores relacionados ao consumo de água e energia para identificar a atividade informal de reforma. As mudanças efetuadas em ligações de água preexistentes estão correlacionadas às ampliações e reformas realizadas informalmente pelos habitantes. O mesmo deve ser válido para as mudanças efetuadas em ligações de energia preexistentes.

Neste estudo, foram consideradas, para fins de estimativa da geração de RCD, as solicitações das ligações de água na Companhia de Saneamento Básico do Estado de São Paulo (SABESP), nos últimos três anos. Para obtenção dos dados de geração anual acumulada dos resíduos pela reforma (R), foram coletadas informações relativas ao número de transformações de ligações de água já existentes nas residências (Tabela 1).

No estudo, admitiu-se que uma reforma residencial não ultrapassa 25\% da área média construída, seja pela maior exposição aos agentes de fiscalização do Conselho Regional de Engenharia, Arquitetura e Agronomia do Estado de São Paulo (CREA) ou pelo aumento de riscos estruturais envolvidos em tais obras. O volume de reforma no município em estudo foi de $30 \mathrm{~m}^{2}$. A título de comparação, na Flórida, Estados Unidos, o valor médio foi de $60 \mathrm{~m}^{2}$ (COCHRAN et al., 2007). Os valores encontrados nessas regiões estão compatíveis com os respectivos produtos interno bruto (PIB).

Aplicando-se uma relação entre a área média reformada para cada ponto de transformação de ligação e o índice de geração por $\mathrm{m}^{2} \mathrm{de}$ área reformada (MORALES et al., 2006), obteve-se uma massa de resíduo gerado por meio da Equação 2

$\mathrm{R}=\mathrm{P} \times \eta \times \rho_{\mathrm{R}}$

Equação 2

onde:

R: resíduo na reforma por mês (t RCD/mês);

P: solicitações de transformação nas ligações de água ou de energia (ligações/mês);

$\eta$ : conversão da área reformada média para cada ligação $\left(30 \mathrm{~m}^{2}\right.$ reforma/ligação);

$\rho_{\mathrm{R}}$ : índice de geração de resíduo na reforma $\left(0,470\right.$ t $\mathrm{RCD} / \mathrm{m}^{2}$ reforma), obtido por Morales et al. (2006).

Em 2009, uma média de 45 ligações por mês foi estimada pela empresa concessionária local de energia. Assim, admitiu-se 540 ligações ao longo dos 12 meses. Nesse ano, o número de alvarás de construção concedidos foi 118. Assim, foram calculadas 422 transformações de pontos de energia elétrica no ano. Multiplicando-se pelas constantes $\left(\eta\right.$ e $\rho_{R}$ ), a geração de resíduos de reforma, em função da transformação dos pontos de energia elétrica, foi comparada com aquela obtida em função da transformação dos pontos de água. 
Tabela 1 - Transformação dos pontos de água nos últimos três anos

\begin{tabular}{lccc|} 
Meses & 2007 & 2008 & 2009 \\
\hline Janeiro & 21 & 52 & 18 \\
\hline Fevereiro & 16 & 41 & 14 \\
\hline Março & 15 & 42 & 19 \\
\hline Abril & 13 & 57 & 14 \\
\hline Maio & 19 & 55 & 17 \\
\hline Junho & 23 & 30 & 20 \\
\hline Julho & 17 & 63 & 17 \\
\hline Agosto & 21 & 47 & 15 \\
\hline Setembro & 18 & 49 & 13 \\
\hline Outubro & 20 & 48 & 20 \\
\hline Novembro & 17 & 58 & $20\left(^{*}\right)$ \\
\hline Dezembro & 16 & 47 & $20\left(^{\star}\right)$ \\
\hline Total & 216 & 589 & 207
\end{tabular}

(*) Valor não-disponível. Admitido com base no último mês.

\section{Quantificação do RCD pelo método direto}

O município foi dividido em 15 regiões, agrupando-se bairros com condições semelhantes de renda populacional, desde que contidos num diâmetro máximo de $1 \mathrm{~km}$. Um levantamento de campo foi realizado durante um mês nas 15 regiões, identificando-se o volume e a origem dos resíduos ( $\mathrm{C}$ ou $\mathrm{R}$ ), próximas às obras, dividindo-os conforme já foi descrito. A forma de transporte do resíduo (caçamba, carroça, entre outros) e sua disposição (ruas, terrenos, córregos, botas-foras) também foram analisadas. O resíduo coletado por caçamba e carroça foi destinado a um bota-fora. A distribuição e o volume de RCD disposto acumulado foram analisados em função das 15 regiões definidas. Por meio da compilação desses resultados, obteve-se uma geração de RCD para cada região do município em função dos diferentes agentes geradores.

\section{Avaliação comparativa dos métodos de quantificação adotados}

Uma análise comparativa entre os métodos de quantificação (direto e indireto) foi realizada com base nos dados médios anuais, assumindo-se a premissa de que a geração indireta de RCD, representada pela soma do resíduo gerado por $\mathrm{C}$ e $\mathrm{R}$, deve ser igual ao volume de RCD encontrado diretamente nos locais de disposição, multiplicado pela sua massa unitária (Equação 3).

$$
\mathrm{C}+\mathrm{R}=\mathrm{V}_{\mathrm{RCD}} \times \gamma_{\mathrm{RCD}}
$$

Equação 3

onde:

C: resíduo gerado na construção por mês (t RCD/mês);

R: resíduo gerado na reforma por mês (t RCD/mês);

$\mathrm{V}_{\mathrm{RCD}}$ : volume disposto de resíduo de construção e demolição $\left(\mathrm{m}^{3}\right.$ RCD/mês);

$\gamma_{\mathrm{RCD}}$ : massa unitária do resíduo de construção e demolição $\left(\mathrm{t} / \mathrm{m}^{3}\right)$, adotada como $1 \mathrm{t} / \mathrm{m}^{3}$ com base em levantamento de campo realizado pelos autores.

\section{Composição do RCD}

Durante o período de quantificação de RCD, amostrou-se uma caçamba por dia em diferentes horários e proveniente de diferentes regiões do município, totalizando dez caçambas para caracterização e definição da composição do RCD dentro das classes A, B. C e D, conforme resolução CONAMA 307. Os RCD das dez caçambas foram misturados por meio de uma retroescavadeira e reduzidos sucessivamente por quarteamento, até a obtenção de uma amostra de $3 \mathrm{~m}^{3}$.

Essa amostra foi transportada para o laboratório, onde foi homogeneizada pela técnica de pilha alongada (PETERSEN, 2004) e dividida em uma alíquota de $500 \mathrm{~kg}$. Esta alíquota foi sucessivamente quarteada até a obtenção de duas amostras de $5 \mathrm{~kg}$, utilizadas para segregação e quantificação dos materiais representantes de cada classe, de acordo com a norma NBR 15116 (ABNT, 2004), aplicável aos agregados reciclados de RCD.

\section{Resultados e Discussão}

\section{Quantificação do RCD pelo método indireto (C e R)}

O município em estudo é caracterizado predominantemente por residências térreas, com área média de construção de $118 \mathrm{~m}^{2}$. Para 2007, 2008 e 2009, as gerações acumuladas de resíduos da construção foram 2.537 t, 3.675 t e 2.398 t (Figura 1a), respectivamente. Para os três anos estudados, a média foi de 2.870 t.

As solicitações de transformação dos pontos de água acumulados ao longo dos meses variaram entre 200 e 600 pedidos no ano (Tabela 1). Multiplicando-se as transformações dos pontos pela área média reformada $\left(30 \mathrm{~m}^{2}\right)$, por ligação e pelo índice de geração de 0,470 t RCD/m² de reforma (MORALES et al., 2006), obtêm-se as massas de resíduos de reforma acumuladas nos últimos três anos (Figura 1b).

As estimativas realizadas pelas solicitações de transformação dos pontos de energia elétrica foram superiores às solicitações de transformação dos pontos de água para 2009 (Tabela 2). Nesse ano, o coeficiente de correlação entre a transformação dos pontos de energia elétrica e a dos pontos de água foi igual a 2,04.

$\mathrm{Na}$ Tabela 3, a média de resíduos de reforma obtidos a partir das transformações dos pontos de água nos últimos três anos foi de 4.851 toneladas. Admitindo-se o mesmo coeficiente de correlação $(2,04)$, infere-se uma média de 9.894 toneladas de resíduos de reforma a partir das transformações dos pontos de energia elétrica.

\section{Quantificação do RCD pelo método direto (disposição)}

A Figura 2 apresenta os dois pontos de disposição final do RCD no município: bota-fora ou ruas/terrenos. Os resíduos gerados em 
cada região foram somados pelo conceito de balanço de massa, totalizando 4.896 e $8.327 \mathrm{~m}^{3} / \mathrm{ano}$, respectivamente. Nesse caso, 37\% do $\operatorname{RCD}\left(4.896 \mathrm{~m}^{3} / \mathrm{ano}\right)$ foram depositados ilegalmente em bota-fora e o restante está disposto irregularmente em ruas e terrenos. A distribuição e pequena concentração dos RCD nas ruas e terrenos dificultam a percepção de tal montante disposto.

Pequenos geradores de obras de reforma correspondem a, no máximo, 10\% do RCD disposto irregularmente na cidade. Devido à inabilidade gerencial, cabe ao poder público implantar pontos de entrega voluntária (PEV). Para este município, um único PEV seria capaz de absorver esse tipo de gerador.

Vale ressaltar que são observados grandes geradores de resíduos de reforma nas demais regiões principais (F, G, B e A). Para o volume considerado, o cidadão (gerador), mediante ações de educação ambiental, poderia ser responsável pela destinação aderente ao plano de gerenciamento municipal, por meio do controle das fichas de transporte e contratação das empresas de caçambas reconhecidas pela Prefeitura, sem precisar dos PEV.

Uma proposta de gerenciamento eficaz precisa estar focada nesse tipo de gerador e não se resolverá apenas com a disponibilização de PEV. Talvez seja esta característica que impeça o progresso da resolução CONAMA 307. Frente ao pequeno investimento em educação ambiental para os agentes geradores de reforma, muitos desconhecem a possibilidade do uso dessas áreas de manejo. Estratégias de gerenciamento capazes de minimizar a geração são bastante interessantes, tais como: a proibição da venda de cimento no varejo; os subsídios fiscais para materiais e práticas de construção racionalizada (por meio de pré-fabricação e automontagem de residências) e reforma (por meio de revestimentos novos - tintas, pisos ou azulejos - aderentes aos revestimentos antigos, que não requeiram atividades parciais de demolição), que gerem pouco resíduos. Tais estratégias evitam investimentos em áreas de manejo e descentralizam ações gerenciais

A Tabela 4 apresenta uma síntese da geração de RCD no município em função dos agentes geradores e regiões. As construtoras não se caracterizam como os maiores agentes geradores do RCD (18\%

Tabela 2 - Resíduo de reforma pela transformação dos pontos de água e de energia em 2009

\begin{tabular}{|lccc} 
Fonte & $\begin{array}{c}\text { Transformação } \\
\text { dos pontos (un) }\end{array}$ & Reforma $\left(\mathrm{m}^{2}\right)$ & $\begin{array}{c}\text { Resíduo } \\
\text { da reforma }(\mathrm{t})\end{array}$ \\
\hline Água & 207 & 6.210 & 2.919 \\
\hline Energia & 422 & 12.660 & 5.950
\end{tabular}

Tabela 3 - Estimativa do resíduo de reforma (t) no município, nos últimos três anos

\begin{tabular}{lcccc} 
& \multicolumn{4}{c}{ Resíduo de reforma no ano $(\mathrm{t})$} \\
Fonte & 2007 & 2008 & 2009 & Média \\
\hline Água & 3.328 & 8.305 & 2.919 & 4.851 \\
\hline Energia & - & - & 5.950 & $9.894\left(^{*}\right)$ \\
\hline
\end{tabular}

(*) $4.851 \times 2,04$.

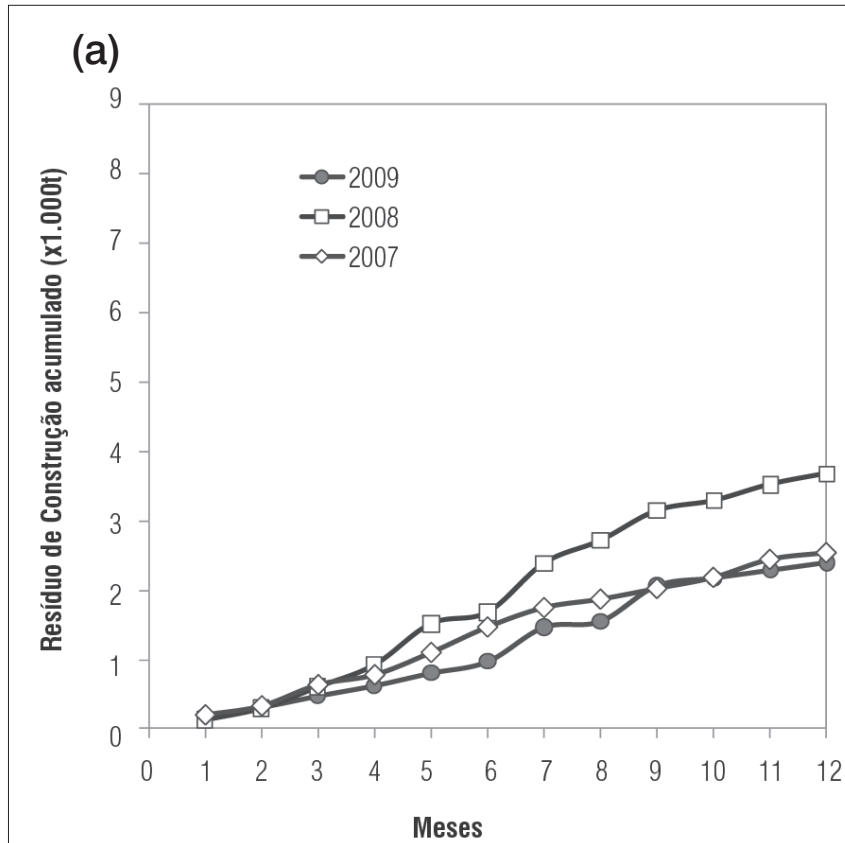

(b)

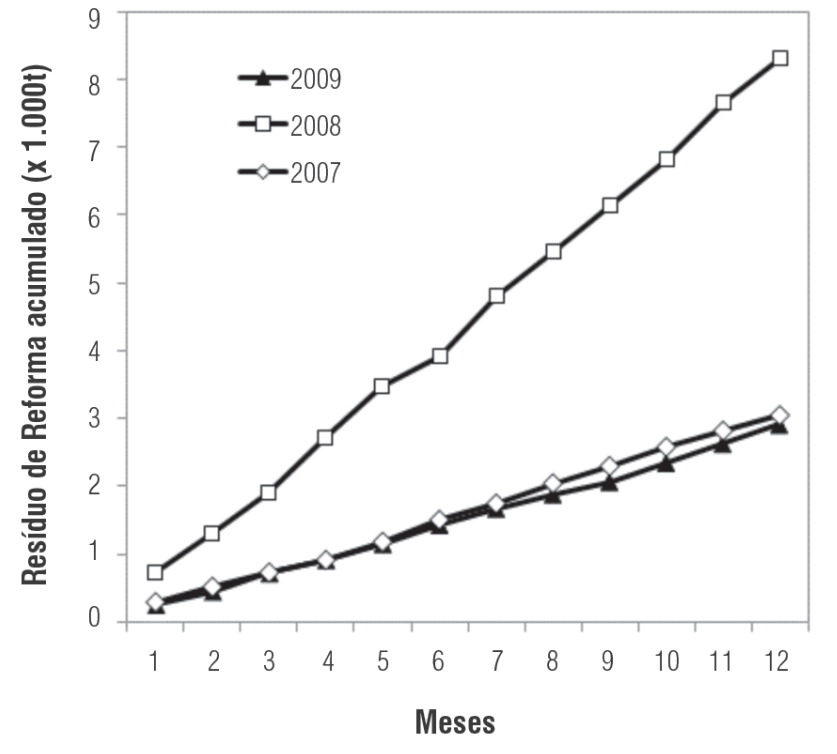

Figura 1 - (a) Resíduos acumulados de construção (a) e resíduos acumulados de reforma, em função dos pontos de transformação de água (b).

Tabela 4 - Geração de RCD (t/dia) em função dos agentes geradores e regiões

\begin{tabular}{lcccc} 
& \multicolumn{4}{c}{ Geração de RCD (t/dia) } \\
\cline { 2 - 5 } Regiões & Construtoras & $\begin{array}{c}\text { Grandes } \\
\text { reformas }\end{array}$ & $\begin{array}{c}\text { Pequenas } \\
\text { reformas }\end{array}$ & Total \\
\hline A & 0,8 & 8,9 & 1,0 & 10,8 \\
B & 1,9 & 3,3 & 0,6 & 5,9 \\
\hline C & 4,6 & 0,3 & 0,4 & 5,3 \\
\hline F & 0,4 & 4,3 & 0,4 & 5,1 \\
G & 0,1 & 5,7 & 0,2 & 6,1 \\
\hline Média (10 regiões) & 0,1 & 1,4 & 0,2 & 1,7 \\
Total $\left(^{*}\right)$ & 8,8 & 36,8 & 4,5 & 50,1 \\
\hline
\end{tabular}

(*) Total $=$ A + B + C + F+ G + Média*10. 


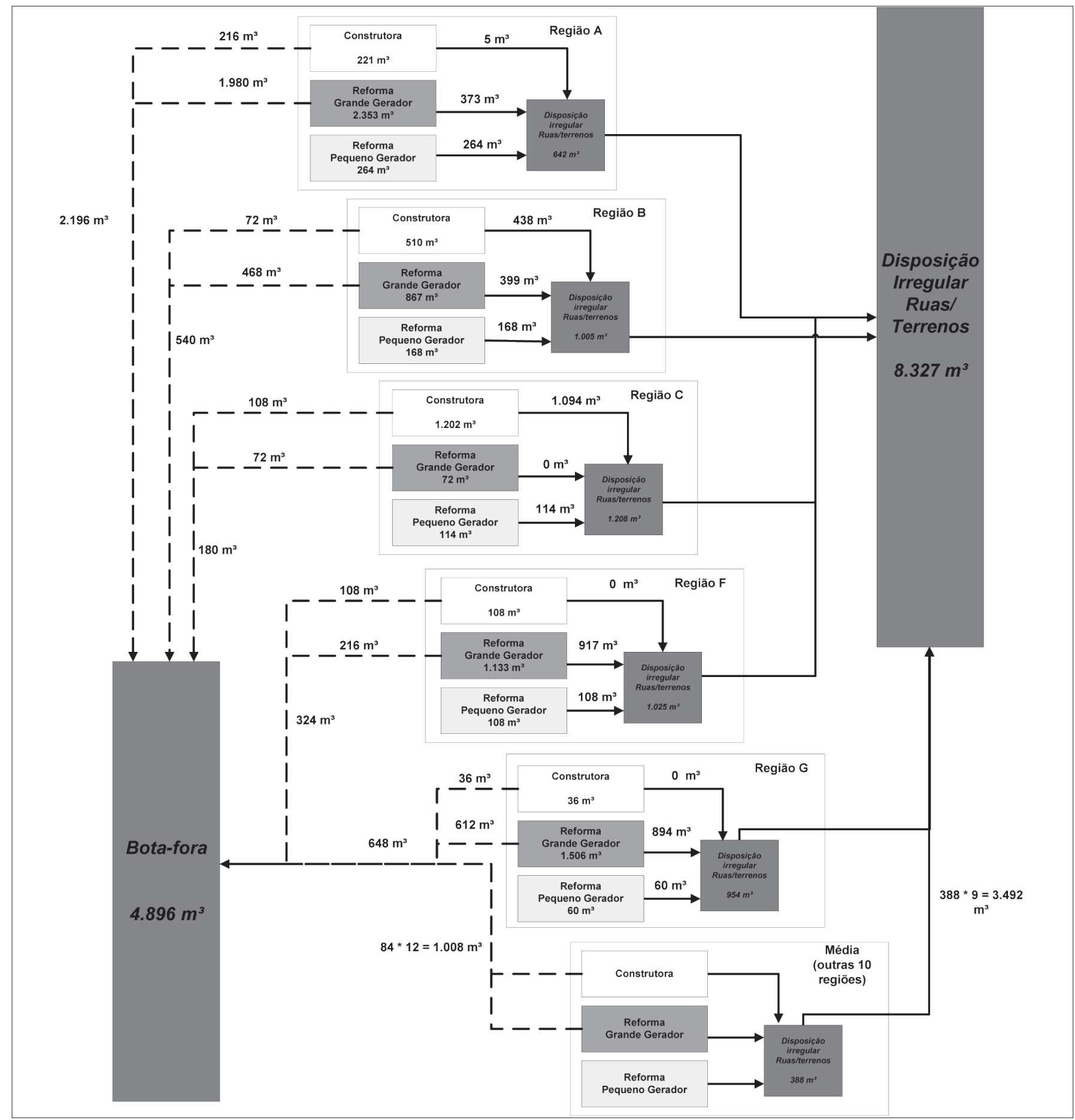

Figura 2 - Balanço de massa do RCD na disposição para 2009.

do total). Esse dado é confirmado para diversos municípios paulistas, de acordo com Pinto et al. (2005), variando entre 27 e 51\%. A grande maioria dos RCD é gerada pelas grandes reformas, que geram aproximadamente 37 toneladas/dia (73\% do total), enquanto apenas 5 toneladas/dia são geradas por pequenas reformas ( $9 \%$ do total). Devido à ausência de empresas demolidoras (grandes geradores legalizados) em pequenos municípios, a importância relativa das reformas é ainda maior.

\section{Avaliação comparativa dos métodos}

A Tabela 5 apresenta a análise comparativa da geração média dos RCD pelos métodos indireto e direto, em 2009, e pela média dos últimos três anos. Como as obras residenciais têm duração geralmente inferior a um ano, é razoável afirmar que a quantificação indireta (soma da metragem quadrada por alvarás de construção e índice de geração médio) é muito semelhante à direta para 2009. O cálculo 
pela média dos últimos três anos superestima este valor. Isto pode não ser válido para regiões em que a presença de edificações multiandares é significativa, porque o prazo de execução das obras se altera para dois ou três anos.

No caso das obras de reforma, sabe-se que a estimativa indireta pela geração por transformações dos pontos de água subestima significativamente aquela encontrada pelo método direto. Como a média disponibilizada dos pontos de energia elétrica para 2009 é superior aos de água, admite-se que esse indicador seja mais preciso para se correlacionar com atividades de reforma, especialmente porque o valor agregado do serviço prestado é superior ao outro, indicando qualquer atividade econômica fora da normalidade ou aumento da população numa residência.

A geração dos resíduos de reforma, calculada pelas transformações dos pontos de energia, ficou também subestimada para 2009, porque o indicador de geração não é suficiente preciso, uma vez que reformas menores e pontuais podem não ser quantificadas por esse tipo de indicador, tais como trocas de pisos ou revestimentos. O consumo de cimento no varejo pode ser um indicador ainda mais preciso, cabendo maiores investigações. Como a quantidade de resíduo gerada numa reforma pontual (troca de piso ou azulejos) é inferior à quantidade gerada numa ampliação, a imprecisão do estimador pode estar vinculada ao fato de que não se remove, com frequência, durante a limpeza pública, os resíduos de reforma, permanecendo nas ruas por mais de um ano. Nesse último caso, pode ser mais preciso realizar estimativas médias pela origem (método indireto).

Com base no método direto, os resíduos de reforma correspondem a $82 \%$ da massa do RCD gerado no município. Obras de reforma são as principais geradoras de RCD. Essa realidade é confirmada para a maioria dos municípios paulistas investigados pelo Ministério das Cidades (PINTO et al., 2005). A geração per capita média de RCD está em torno de 367 kg/habitantes, por ano, e apresenta correlação com o índice de desenvolvimento humano (IDH) para os municípios paulistas (Figura 3), conforme já apontado por Careli (2008) e Benvenuto e Suzuki (2009). Estes autores utilizaram esse indicador para prever a geração futura de RCD, numa determinada região, e dimensionar mais apropriadamente os instrumentos de gestão do RCD (PEV, áreas de transbordo e triagem, usina de reciclagem, entre outros).

\section{Composição média de RCD obtida no estudo}

A composição média dos RCD analisados no presente estudo está apresentada na Tabela 6. Observa-se a predominância do RCD na Classe A, 91\% da massa, e 9,0\% de Classe B, não sendo quantificados componentes pertencentes às Classes C e D. Resultados semelhantes são apresentados nos estudos nacionais e na maioria dos internacionais (ANGULO, 2005), com exceção de alguns países (EUA, devido ao uso intenso de madeira, dentre outros).
Tabela 5 - Estimativa do RCD (t/ano ou kg/hab. ano) pela origem e destino

\begin{tabular}{lccccccc} 
RCD & $\begin{array}{c}\text { Método } \\
\text { indireto } \\
(2009)\end{array}$ & $\begin{array}{c}\text { Método } \\
\text { direto }\end{array}$ & $\begin{array}{c}\text { Diferença } \\
(\mathrm{em} \%)\end{array}$ & $\begin{array}{c}\text { Método } \\
\text { indireto } \\
\text { (três anos) }\end{array}$ & $\begin{array}{c}\text { Método } \\
\text { direto }\end{array}$ & $\begin{array}{c}\text { Diferença } \\
(\mathrm{em} \%)\end{array}$ \\
\hline Construção $(\mathrm{t})$ & 2.398 & 2.329 & -3 & 2.870 & 2.329 & -23 \\
\hline Reforma (t) & 5.950 & 10.894 & 45 & 9.894 & 10.894 & 9 \\
\hline Total (t) & 8.348 & 13.223 & 37 & 12.764 & 13.223 & 3 \\
\hline
\end{tabular}

Tabela 6 - Composição do RCD (\% em massa) no município

$\begin{array}{lc}\text { Classes do RCD pela CONAMA } 307 & \text { Massa (\%) } \\ \text { Classe A } & 91,0 \\ \text { Classe B } & 9,0 \\ \text { Classe C } & 0,0 \\ \text { Classe D } & 0,0\end{array}$

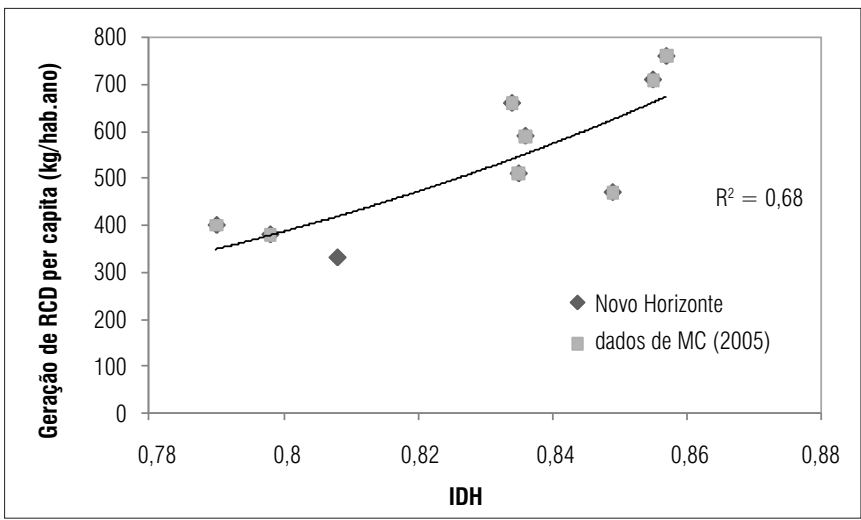

Figura 3 - IDH versus geração de RCD per capita.

\section{Conclusões}

Não é possível quantificar indiretamente a geração dos agentes informais (reformas), por meio das transformações dos pontos de água. Há indícios que as transformações dos pontos de energia elétrica sejam indicadores mais precisos, bem como não deve ser descartada a possibilidade do uso de outros indicadores (consumo de cimento no varejo). A metodologia de quantificação indireta, ainda indisponível na literatura, pode eliminar a necessidade de quantificação direta, que é dispendiosa para a implantação da gestão de RCD. Quanto ao uso do método direto, o artigo ainda propõe a identificação do tipo de gerador, próximo ao local de geração, por região, e cálculo do balanço de massa, conferindo um grau de importância por regiões. Tal método pode descentralizar as ações e reduzir os custos do programa de gestão. Na ausência de dados validados cientificamente, recomenda-se a adoção de ambos os métodos, pois viabilizam a verificação da consistência dos dados.

\section{Agradecimentos}

Agradecemos ao Programa de Apoio Tecnológico aos Municípios (PATEM) da Secretaria de Desenvolvimento Econômico, Ciência e Tecnologia do Governo do Estado de São Paulo e à Prefeitura de Novo Horizonte, bem como Sidnei Rodrigues de Oliveira (levantamento de dados) e Ana Paula Shibata (revisão). 


\section{Referências}

ANGULO, S.C. Caracterização de agregados de resíduos de construção e demolição reciclados e a influência de suas características no comportamento mecânico dos concretos. 2005. 149 f. Tese (Doutorado em Engenharia Civil) - Escola Politécnica da Universidade de São Paulo, São Paulo, 2005.

ASSOCIAÇÃO BRASILEIRA DE NORMAS TÉCNICAS (ABNT). NBR 15.116: agregados de resíduos sólidos da construção civil: utilização em pavimentação e preparo de concreto sem função estrutural requisitos. Rio de Janeiro, 2004.

BENVENUTO, C.; SUZUKI, F.K.S. Plano integrado de gerenciamento regional de resíduos de construção civil e volumosos. Revista Limpeza Pública, n. 71, p. 6-11, 2009.

BRASIL. Lei no 12.305, de 2 de agosto de 2010: institui a Política Nacional de Resíduos Sólidos; altera a Lei n 9.605, de 12 de fevereiro de 1998; e dá outras providências. Diário Oficial da União, Brasília, DF, 3 ago. 2010.

CARELI, E.D. A resolução CONAMA n. 307/2002 e as novas condições para a gestão dos resíduos de construção e demolição. 2008. 155 p. Dissertação (Mestrado em Engenharia Civil) - Centro Estadual de Educação Tecnológica Paula Souza, São Paulo, 2008.

COCHRAN, K.M.; TOWNSEND, T.G. Estimating construction and demolition debris generation using a materials flow analysis approach. Waste Management, v. 30, n. 11, p. 2247-2254, 2010.

COCHRAN, K. M. et al. Estimation of regional building-related C\&D debris generation and composition: Case study for Florida, US. Waste Management, v. 27, n. 7, p. 921-931, 2007.

Conselho Nacional do Meio Ambiente (CONAMA). Resolução n ${ }^{\circ} 307$, de 05 de julho de 2002: Estabelece diretrizes, critérios e procedimentos para a gestão dos resíduos da construção civil. Diário Oficial da União, Brasília, DF, 17 jul. 2002.

COSTA, N. da et al. Planejamento de programas de reciclagem de resíduos de construção e demolição no Brasil: uma análise multivariada. Revista Engenharia Sanitária, v. 12, n. 4, p.446-456, 2007.

HSIAO, T.Y. et al. Modeling materials flow of waste concrete from construction and demolition wastes in Taiwan. Resources Policy, v. 28, n. 1-2, p.39-47, 2002.

Instituto Brasileiro de Geografia e Estatística (IBGE). Ministério do Planejamento, Orçamento e Gestão. Censo 2010. Disponível em: <http://www.ibge.gov.br/home/default.php>. Acesso em: 06 jun. 2011.

JOHN, V.M. Reciclagem de resíduos na construção civil - contribuição a metodologia de pesquisa e desenvolvimento. 2000. 102 p. Tese (livre- docência) - Escola Politécnica da Universidade de São Paulo, São Paulo, 2000.

LAGE, I.M. et al. Estimation of the annual production and composition of C\&D debris in Glicia (Spain). Waste Management, v. 30, n. 4, p. 636-45, 2010.

LLATAS, C. A model for quantifying construction waste in projects according to the European waste list, Waste Management, v. 31, n. 6, p. 1261-1276, 2011.

MARQUES NETO, J.C. Estudo da gestão municipal dos resíduos de construção e demolição na Bacia Hidrográfica do Turvo Grande. 2009. 629 p. Tese (Doutorado em Ciências da Engenharia Ambiental) - Escola de Engenharia de São Carlos, Universidade de São Paulo, 2009.

MIRANDA, L.; ANGULO, S.C.; CARELI, E.D. A reciclagem de resíduos de construção e demolição no Brasil: 1986-2008. Ambiente Construído (Online), v. 9, n. 1, p. 57-71, 2009.

MORALES, G; MENDES, T.; ANGULO, S.C. Índices de geração de RCD provenientes de obras de construção, reforma e demolição na cidade de Londrina/PR. In: II Congresso Internacional na Recuperação, Manutenção e Restauração de Edificações, 2006, Rio de Janeiro. Anais... (CD-ROM). Rio de Janeiro: 2006. v. 1.

PETERSEN, I.F. Blending in circular and longitudinal mixing piles. Chemometrics and Intelligent Laboratory Systems, v. 74, n. 1, p. 135141, 2004.

PINTO, T.P. Gerenciamento de resíduos da construção no Brasil. In: RCD08, Universidade de São Paulo, São Paulo. Apresentação (CDROM). São Paulo, 2008. Disponível em: <http://rcd08.pcc.usp.br>. Acesso em: 6 jun. 2011.

Metodologia para a gestão diferenciada de resíduos sólidos da construção urbana. 1999. 189 f. Tese (Doutorado em Engenharia Civil) - Escola Politécnica da Universidade de São Paulo, São Paulo, 1999.

PINTO, T. P. et al. Ministério das Cidades. Manejo e gestão de resíduos da construção civil: como implantar um sistema de manejo e gestão nos municípios. v. 1. 196 p. Brasília: Caixa, 2005.

SOLIS-GUZMAN, J. et al. A Spanish model for quantification and management of construction waste. Waste Management, v. 29, n.9, p. 2542-2548, 2009.

SOUZA, U.E.L. et al. Diagnóstico e combate à geração de resíduos na produção de obras de construção de edifícios: uma abordagem progressiva. Ambiente Construído, v. 4, n. 4, p. 33-46, 2004.

WANG, J. Y. et al. A systems analysis tool for construction and demolition wastes management. Waste Management, v. 24, n. 10, p. 989-997, 2004. 